\title{
Is bipolar disorder linked to Xq28?
}

Sir - In the January 1993 issue of Nature Genetics diminished support forlinkage between manic-depressive illness (MDI), also known as bipolar disorder, and chromosome Xq2728 markers was reported by Baron $e t$ $a l .{ }^{1}$. Previous studies using Xq28 pheno-typic markers - colourblindness and glucose-6-phosphate dehydro-genase (G6PD) deficiency - had provided evidence for linkage in a proportion of pedigrees (see ref. 2 for review), following an earlier report ${ }^{3}$, speculating that $\mathrm{X}$-linked inheritance may be more pronounced among Mediterranean and Asian communities ${ }^{3}$.

We began to study MDI pedigrees after Mendlewicz et al. ${ }^{4}$ reported strong evidence for linkage between G6PD deficiency and MDI in a Persian

Table 1 Prevalences of G6PD deficiency in psychiatric patients

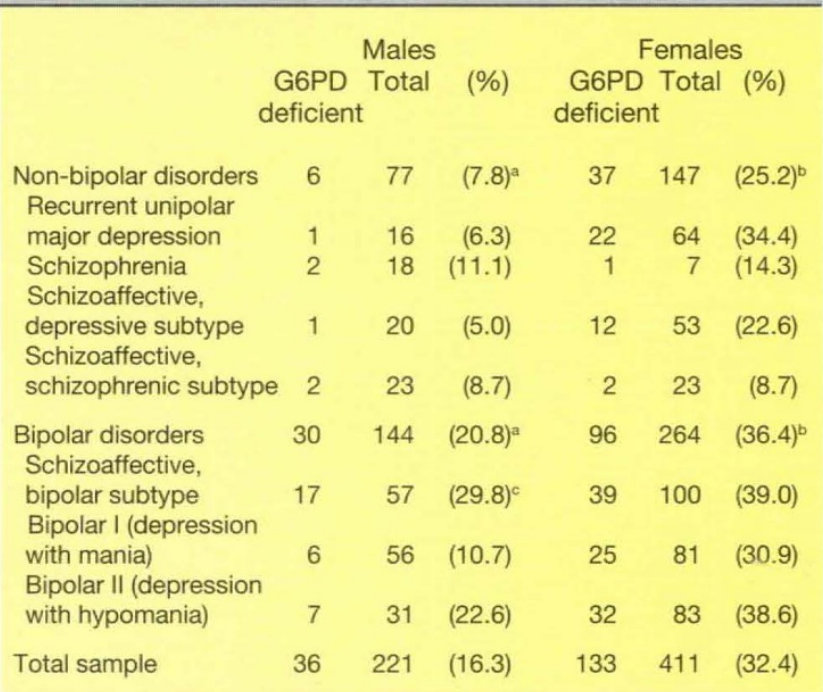

Subjects are 632 consecutive outpatients admitted to the Centre of Clinical Psychopharmacology, Department of Neurosciences, University of Cagliari, between 1984 and 1993, and patients admitted over the previous 8 years if still attending the Centre. Modified research diagnostic criteria $(\mathrm{RDC})^{10}$ were applied to direct interview, medical records and information from relatives and referring psychiatrists. G6PD phenotypes were established using quantitative assays on erythrocytes ${ }^{11}$ or whole blood samples ${ }^{12}$, assigning females according to the ranges calculated in males. The overall phenotype distribution is in agreement with a Hardy-Weinberg distribution. G6PD determinations and psychiatric diagnosis were always done blind with respect to each other. The female G6PD deficient group in this table includes subjects with activity in either the homozygous or heterozygous range. The following statistical differences were observed using Fisher's exact test (all reported $P$ values are two-tailed): bipolar versus non-bipolar disorders, males a $P$ $=0.01$, females ${ }^{\circ} P=0.02$; bipolar schizoaffective disorder versus remaining subgroups, males ${ }^{\circ} P=0.002$.
Jewish pedigree. The high prevalence of G6PD deficiency in Sardinia prompted us to survey G6PD activity in our psychiatric population with the initial aim of identifying pedigrees for an X-linkage study. Unexpectedly, we found an association between G6PD deficiency and bipolar subgroups 6 . So far, we have surveyed G6PD activity in 632 patients (Table 1). The overall prevalences of enzymatic deficiency are within the range found in the general population in Sardinia ${ }^{7}$, but there are significant bipolar/non-bipolar differences in both sexes.

Marker-disease associations exist under three conditions: the marker plays a role in the disease; the marker is closely linked to a disease gene and there is linkage disequilibrium; the sample is a stratified mixture derived from populations with different prevalences of the marker and the disease. Interestingly, a trend towards the same bipolar/non-bipolar distinction was found in Illinois in a small sample of patients ${ }^{8}$, surveyed for G6PD deficiency after the observation of favism-related psychotic episodes?

We are studying marker and disease at the familial level, which is a robust strategy in the face of geographical stratifications. Preliminary results from 27 pedigrees suggest cosegregation of $66 \mathrm{PD}$ deficiency and $\mathrm{MDI}$, based on concordance rates found in affected relatives of bipolar probands (36 out of 40 with any affective disorder; 19 out of 21 with bipolar I, bipolar II or bipolar schizoaffective disorders only). Lod scores are consistent with close linkage, despite reduced informativeness as a result of several pedigrees featuring multiple sources of G6PD deficiency.

A similar event has occurred in the pedigree contributing to the original support of Xq28 linkage reported by Baron t $_{\text {al. }}{ }^{3}$.In the updated pedigree ${ }^{1}$, there are three different sources of G6PD deficiency, considering the homozygosity of the proband and the G6PD deficient spouse with recurrent depression marrying into the pedigree. Overall, 10 out of 11 affectively ill subjects are G6PD deficient. G6PD heterozygotes appear to present a less severe phenotype than homozygotes or hemizygotes. Accordingly, even though support for linkage in that pedigree is greatly reduced, an association between MDI and G6PD deficiency is not ruled out.

Besides using conventional linkage methods, we have also analysed our initial set of pedigrees from the association point of view using the program package SAGE. Withinfamily association between G6PD deficiency and affective disorders is suggested with an approximate $P$ value of 0.025 (reported at the 1993 World Congress on Psychiatric Genetics, New Orleans).

In conclusion, the hypothesis of an Xq28 gene, perhaps G6PD itself, contributing to the susceptibility to MDI in some ethnic groups deserves further consideration, despite being discredited ${ }^{1}$ by some of its original supporters ${ }^{3}$.

\section{Alberto Bocchetta \\ M. Paola Piccardi \\ Maria Del Zompo \\ Department of Neurosciences \\ 'Bernard B. Brodie', \\ University of Cagliari,}

Via Porcell 4 - 09124 Cagliari, Italy

1. Baron, M. et al. Nature Genet. 3, 49-55 (1993)

2. Baron, M. Soc. Biol. 38, 179-188 (1991).

3. Baron, M. et al. Nature 326, 289-292 (1987).

4. Mendlewicz, J. Linkowski, P. \& Wilmotte, J. Brit. J. Psychiat. 137, 337-342 (1980).

5. Del Zompo, M., Bocchetta, A., Goldin, L.R. \& Corsini, G.U. Acta Psychiat. Scand. 70, 282 287 (1984).

6. Bocchetta, A., Severino, G., Bernardi, F. \& Del Zompo, M. Italian J. Psychiat. behav. Sci. 3 . 107-110 (1993).

7. Siniscalco, M. et al. Bull. WHO 34, 379-393 (1966).

8. Nasr, S.J., Altman, E., Pscheidt, G. \& Meltzer, H.J. Biol. Psychiat. 17, 925-928 (1982).

g. Nasr, S.J.Arch. gen. Psychiat. 33, 1202-1203 (1976).

10. Spizzer, R.L., Endicott, J. \& Robins, E. Research Diagnostic Criteria for a Selected Group of Functional Disorders 3rd edn (New York State Psychiatric Institute, New York, 1977). 1. Komberg, A. \& Horecker, B.L. in Methods in Enzymology (eds Colowick, S.P. \& Kaplan, N.O.) 323-327 (Academic Press, New York. 1955).

12. Mosca, A. et al. Haematologica 75, 397-399 (1990).

\section{Acknowledgements}

We thank F. Macciardi for his help. This work was supported by grants from the Regione Autonoma della Sardegna, Assessorato Igiene $e$ Sanitá and by Theodore and Vada Stanley Foundation Research Award (A.B.). 